\title{
Protective effects of salvianolic acid B against hydrogen peroxide-induced apoptosis of human umbilical vein endothelial cells and underlying mechanisms
}

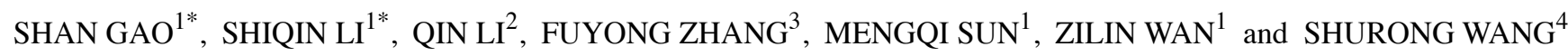 \\ ${ }^{1}$ College of Pharmacy, Southwest Medical University; ${ }^{2}$ Department of Infectious Gastroenterology, \\ Affiliated Hospital of Southwest Medical University, Luzhou, Sichuan 646000; ${ }^{3}$ Department of Pharmacy, \\ People's Hospital of Deyang City, Deyang, Sichuan 618000; ${ }^{4}$ Department of Pharmacy, Affiliated Hospital of \\ Southwest Medical University, Luzhou, Sichuan 646000, P.R. China
}

Received November 27, 2018; Accepted May 23, 2019

DOI: $10.3892 /$ ijmm.2019.4227

\begin{abstract}
Salvianolic acid B (Sal B) is a water-soluble active component of Danshen and has anti-atherosclerotic effects. The present study aimed to evaluate the cytoprotective effects of Sal B against hydrogen peroxide $\left(\mathrm{H}_{2} \mathrm{O}_{2}\right)$-induced oxidative stress damage in human umbilical vein endothelial cells (HUVECs) and investigate the underlying mechanisms. It was revealed that $\mathrm{Sal} \mathrm{B}$ protected the cells from $\mathrm{H}_{2} \mathrm{O}_{2}$-induced damage, as indicated by MTT results showing enhanced cell viability and by flow cytometric analysis showing reduced apoptosis of cells challenged with $\mathrm{H}_{2} \mathrm{O}_{2}$. Furthermore, as an underlying mechanism, the enhancement of autophagy was indicated to be accountable for the decrease in apoptosis, as Sal B caused the upregulation of light chain 3-II and Beclin-1, and downregulation of p62 under $\mathrm{H}_{2} \mathrm{O}_{2}$-induced oxidative stress. Finally, Sal B increased the phosphorylation of AMP kinase (AMPK) and decreased the phosphorylation of mammalian target of rapamycin (mTOR), but had no effect on the phosphorylation of AKT. In conclusion, the present study revealed that Sal B protects HUVECs from oxidative stress, at least partially by promoting autophagy via activation of the AMPK pathway and downregulation of the mTOR pathway.
\end{abstract}

\section{Introduction}

Vascular endothelial cells (ECs) are known serve an important in the entire cardiovascular system $(1,2)$, and they have

Correspondence to: Ms. Shurong Wang, Department of Pharmacy, Affiliated Hospital of Southwest Medical University, 25 Taiping Street, Luzhou, Sichuan 646000, P.R. China

E-mail: lyfywsr@163.com

${ }^{*}$ Contributed equally

Key words: salvianolic acid B, atherosclerosis, apoptosis, autophagy, human umbilical vein endothelial cells anticoagulation and anti-adhesive effects. All stimulating factors can activate vascular ECs and cause cell injury. The injury of vascular ECs by oxidative stress is a major initiator and driving factor in the progression of atherosclerosis $(3,4)$. Therefore, in anti-atherosclerotic treatment, it is key is to reduce the injury and loss of vascular ECs. Studies have indicated that the major type of injury from oxidative damage is apoptosis, which may affect the natural function and structure of vascular ECs, and result in the loss of vascular ECs (4).

Autophagy is a lysosome-dependent catabolic process involving the degradation of long-lived proteins and organelles, and recycling of cytoplasmic components $(5,6)$. It is known that autophagy has a crucial role in maintaining cardiovascular cell functions and structure, and to degrade long-lived proteins and their own organelles (7). It has been indicated that autophagy serves a vital role in cardiovascular disease by regulating EC functions (8).

Salvianolic acid B (Sal B) is the most abundant water-soluble compound extracted from Danshen and possesses anti-oxidative and anti-inflammatory effects. Its chemical structure is presented in Fig. 1. The Chinese medicinal formulation 'Shuangdan oral solution' is used to treat atherosclerosis and one of its major components is Sal B (9); however, the mechanisms of action remain to be fully elucidated. Therefore, the present study further examined the anti-atherosclerotic effects of Sal B and investigated the underlying mechanisms. Previous studies have confirmed that Sal B has anti-oxidative effects and eliminates superoxide anion radicals $\left(\mathrm{O}^{2-}\right)$, thereby suppressing hydrogen peroxide $\left(\mathrm{H}_{2} \mathrm{O}_{2}\right)$-induced apoptosis $(10,11)$. Another study indicated that Sal B promotes human umbilical vein endothelial cell (HUVEC) proliferation (12). However, the mechanisms, including whether autophagy is involved, remain to be fully elucidated. Autophagy and apoptosis are crucial mechanisms in regulating cell survival (13). The possible association between autophagy and apoptosis in the effects of Sal B also remains to be determined. Therefore, the present study aimed to investigate the protective effects of Sal B against $\mathrm{H}_{2} \mathrm{O}_{2}$-induced apoptosis in HUVECs and the underlying mechanisms in order to provide novel approaches for the treatment of atherosclerosis. 


\section{Materials and methods}

Reagents and antibodies. The HUVECs were provided by the Cell Bank of the Chinese Academy of Sciences. Dulbecco's modified Eagle's medium (DMEM) was obtained from Gibco/Invitrogen; Thermo Fisher Scientific, Inc. (Waltham, MA, USA). The MTT kit was purchased from Beyotime Institute of Biotechnology. Hoechst 33258, the Caspase 3 Activity Assay kit, adenovirus (Ad)-mCherry-green fluorescence protein (GFP)-light chain (LC)3B and the bicinchoninic acid (BCA) Protein Assay kit were all purchased from Beyotime Institute of Biotechnology. Antibodies against p62 (cat. no. ab109012; 1:10,000), LC3-II (cat. no. ab192890; 1:2,000), AMPK (cat. no. ab32047; 1:1,000), phosphorylated (p)-AMPK (cat. no. ab131357; 1:500), cytochrome $c$ (cat. no. ab133504; 1:5,000), AKT (cat. no. ab179463; 1:10,000), p-AKT (cat. no. ab81283; 1:5,000), caspase 3 (cat. no. ab32351; 1:5,000), mammalian target of rapamycin (mTOR; cat. no. ab32028; 1:1,000) and p-mTOR (cat. no. ab109268; 1:1,000) were purchased from Abcam (Cambridge, MA, USA), and antibody against Beclin-1 (cat. no. 3495T; 1:1,000) was obtained from Cell Signaling Technology, Inc. (Danvers, MA, USA). $\beta$-actin (cat. no. bs-0061R; $1: 5,000$ ) and goat anti-mouse IgG (cat. no. bs-0295GS; 1:2,000) were obtained from Bioss Biotechnology (Beijing, China). 3-Methyladenine (3-MA) (Selleck, Houston, TX, USA) was used to inhibit autophagy the and mTOR inhibitor, rapamycin (Selleck, Houston, TX, USA), was used to activate autophagy. Compound $\mathrm{C}$ was purchased from Calbiochem (VWR, Lutterworth, UK).

Cell culture. The HUVECs were grown in DMEM supplemented with $10 \%$ fetal bovine serum (GIBCO/Invitrogen; Thermo Fisher Scientific, Inc.) in an incubator at $37^{\circ} \mathrm{C}$ and in a humidified atmosphere with $5 \% \mathrm{CO}_{2}$. The HUVECs were pre-treated with Sal B $(5,10$ or $20 \mu \mathrm{g} / \mathrm{ml})$ for $24 \mathrm{~h}$, following which the liquids were removed and $\mathrm{H}_{2} \mathrm{O}_{2}(800 \mu \mathrm{M})$ was added for $24 \mathrm{~h}$ at $37^{\circ} \mathrm{C}$.

Cell viability assay. An MTT assay was used to assess the cell viability, as described previously (14). The HUVECs were cultured in 96-well plates (5,000 per well) and incubated at $37^{\circ} \mathrm{C}$ for $12 \mathrm{~h}$. Following the different treatments, $10 \mathrm{ml}$ MTT solution at a 1:10 dilution was added to each well, followed by incubation at $37^{\circ} \mathrm{C}$ for $40 \mathrm{~min}$. The absorbance at $450 \mathrm{~nm}$ was detected with a microplate reader (Bio-Rad 550; Bio-Rad Laboratories, Inc.). The optical density (OD) was used to determine the percentage of viable cells via the following formula: Cell viability $(\%)=\left(\mathrm{OD}_{\text {treatment group }}-\mathrm{OD}_{\text {blank }}\right.$ group $\left./ \mathrm{OD}_{\text {control group }}-\mathrm{OD}_{\text {blank group }}\right) \times 100 \%$.

Hoechst 33258 fluorescence staining. The HUVECs received the same treatments as described above, followed by a wash with PBS and fixing with $0.5 \mathrm{ml} 4 \%$ paraformaldehyde for $15 \mathrm{~min}$. Following rinsing twice with PBS, the cells were stained with $0.5 \mathrm{ml}$ Hoechst $33258(5 \mathrm{mg} / \mathrm{ml})$ for $15 \mathrm{~min}$ and examined under a fluorescence microscope. HUVECs exhibited a normal nuclear size and uniform fluorescence, whereas apoptotic cells membrane exhibited increased permeability, chromatin shrinkage and denser apoptotic nuclei.
Flow cytometric analysis. An Annexin V-FITC/propidium iodide (PI) dual staining detection kit was used to detect apoptosis in compliance with the manufacturer's protocols. Following treatment, the HUVECs were washed twice in cold PBS, and the cells were then stained with Annexin V-FITC and PI in binding buffer for $15 \mathrm{~min}$ at room temperature in the dark. The cells were subsequently examined by flow cytometry.

Caspase- 3 activity assay. The activity of caspase- 3 was measured using the caspase-3 activity kit (Beyotime Institute of Biotechnology). Cellular extracts $(50 \mu \mathrm{l})$ were incubated in a 96-well microtiter plate with $2 \mathrm{mM}$ Ac-DEVD-pNA, a substrate of active caspase- 3 , for $2 \mathrm{~h}$ at $37^{\circ} \mathrm{C}$. Caspase activity was measured by cleavage of the Ac-DEVD-pNA substrate to pNA (15). The absorbance at $405 \mathrm{~nm}$ was measured by an ELISA reader at room temperature.

$m$ Cherry-GFP-LC3B. The cells were transfected with Ad-mCherry-GFP-LC3B under non-autophagic conditions, following which the mCherry-GFP-LC3B was present in the cytoplasm, as indicated by dispersive yellow fluorescence. Under conditions of autophagy, mCherry-GFP-LC3B is aggregated on the autophagic membrane, visualized as yellow spots. When the autophagosome is fused with lysosomes, the fluorescence of GFP is quenched, with the reagent presents as red spots. The cells were washed twice with PBS, followed by the addition of $1.5 \mathrm{ml}$ fresh medium and transfected with Ad-mCherry-GFP-LC3B adenovirus (Beyotime Institute of Biotechnology), which adopts a mature E1 defective recombinant adenovirus vector system and expresses the fusion protein of red fluorescent protein mCherry, GFP and LC3B in target cells after infection at a MOI of 20 at $37^{\circ} \mathrm{C}$ for $24 \mathrm{~h}$. Following Sal B and $\mathrm{H}_{2} \mathrm{O}_{2}$ treatment, the variations in LC3B fluorescence were recorded with a fluorescence microscope.

Western blot analysis. The levels of p62, LC3-II, AMPK and p-AMPK, cytochrome $c$, AKT, p-AKT, cleaved caspase-3, mTOR and p-mTOR in protein extracts from the HUVECs were detected by western blot analysis. The cells were lysed at $4^{\circ} \mathrm{C}$ for 30 min with RIPA lysis buffer (Beyotime Institute of Biotechnology) containing protease and phosphatase inhibitors, and soluble lysates were harvested via centrifugation at $168 \mathrm{x}$ g for $20 \mathrm{~min}$ at $4^{\circ} \mathrm{C}$ and boiled, and protein concentration was determined with the BCA kit. The protein samples ( $7 \mu$ per lane) were fractionated by SDS-PAGE, the percentage of which was decided by the type of protein. LC3 was used with a $15 \%$ separation gel and the other proteins were used with a $12 \%$ separation gel. Transferred onto a polyvinylidene difluoride membrane (Merck KGaA, Darmstadt, Germany) and then blocked in 5\% skimmed milk powder. The membranes were incubated with primary antibodies for $24 \mathrm{~h}$ and secondary antibody for $1 \mathrm{~h}$ at room temperature. Following washing with tris buffered saline containing $0.1 \%$ Tween-20, the enhanced chemiluminescence western blotting substrate (Merck KGaA) was added to the membranes, which were evaluated using a gel imaging system (Bio-Rad Laboratories, Inc.). The analysis of each protein was performed three times. 


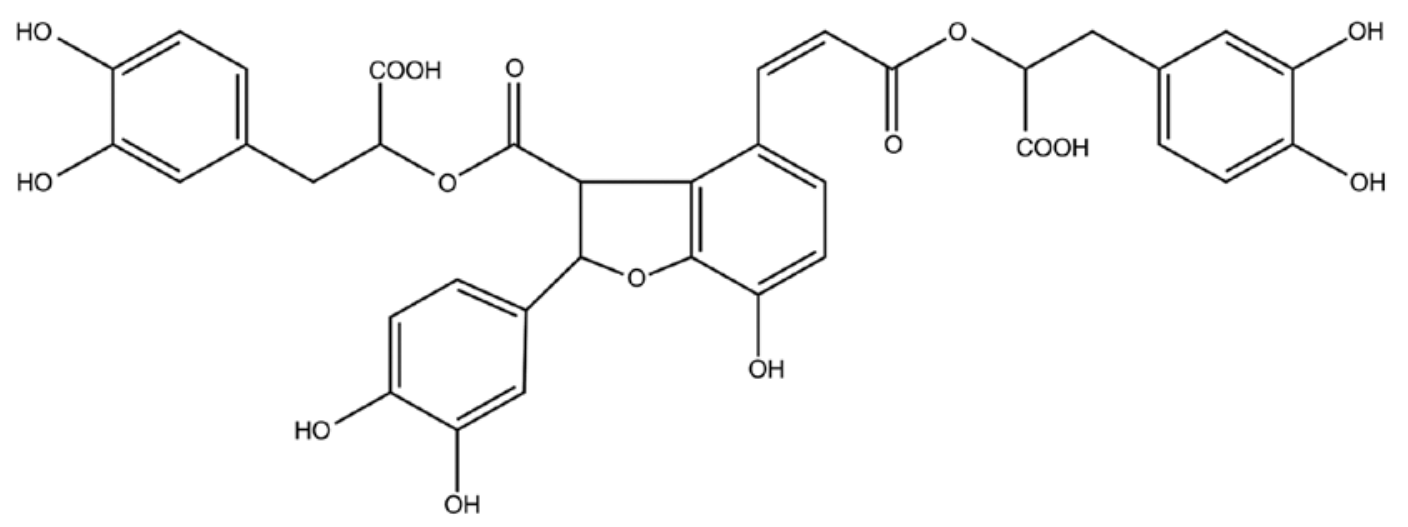

Figure 1. Chemical structure of salvianolic acid B.

Statistical analyses. Data are expressed as the mean \pm standard error of mean. SPSS statistical software (version 17.0; SPSS, Inc., Chicago, IL, USA.) was used for statistical analyses. One-way ANOVA was used for comparison between multiple groups, followed by the Bonferroni post hoc test or unpaired Student's t-test. $\mathrm{P}<0.05$ was considered to indicate a statistically significant difference.

\section{Results}

Sal B protects $\mathrm{HUVECs}$ from $\mathrm{H}_{2} \mathrm{O}_{2}$-induced cytotoxicity. First, the HUVECs were treated with different concentrations of $\mathrm{H}_{2} \mathrm{O}_{2}$ for $24 \mathrm{~h}$ to determine the dose to achieve optimal oxidative stress conditions. The cell viability in the different groups was detected using an MTT assay. As presented in Fig. 2A, an $\mathrm{H}_{2} \mathrm{O}_{2}$ dose-dependent increase in cytotoxicity was observed. The cell viabilities were significantly decreased following treatment with $1,000 \mu \mathrm{M} \mathrm{H}_{2} \mathrm{O}_{2}$. Therefore, $800 \mu \mathrm{M} \mathrm{H}_{2} \mathrm{O}_{2}$ was selected to perform the subsequent experiments. In order to determine the concentration range of Sal B to assess its cytoprotective effect, the HUVECs were first treated with this drug at different concentrations $(5,10,20,40$ and $80 \mu \mathrm{g} / \mathrm{ml})$. When the concentration was increased to $80 \mu \mathrm{g} / \mathrm{ml}$, the cell viability was significantly decreased (Fig. 2B). Therefore, Sal B was used at the concentrations of 5, 10 and $20 \mu \mathrm{g} / \mathrm{ml}$ in the subsequent experiments. To assess the cytoprotective effect of Sal B, the HUVECs were pre-treated with different concentrations of Sal B $(5,10$ and $20 \mu \mathrm{g} / \mathrm{ml})$ for $24 \mathrm{~h}$, followed by incubation with $800 \mu \mathrm{M} \mathrm{H}_{2} \mathrm{O}_{2}$ for $24 \mathrm{~h}$. As presented in Fig. $2 \mathrm{C}$, the cell viability in the $\mathrm{Sal} \mathrm{B}+\mathrm{H}_{2} \mathrm{O}_{2}$ group was increased compared with that in the $\mathrm{H}_{2} \mathrm{O}_{2}$ group, suggesting that Sal B protects HUVECs against $\mathrm{H}_{2} \mathrm{O}_{2}$-induced damage.

Sal $\mathrm{B}$ inhibits apoptosis in HUVECs induced by $\mathrm{H}_{2} \mathrm{O}_{2}$. To determine whether the effect of Sal $\mathrm{B}$ to inhibit the toxicity of $\mathrm{H}_{2} \mathrm{O}_{2}$ to HUVECs was associated with inhibition of inhibition of cell injury and apoptosis in vitro, the HUVECs were pre-treated with different concentrations of Sal B $(5,10$ or $20 \mu \mathrm{g} / \mathrm{ml}$ ) for $24 \mathrm{~h}$, followed by $\mathrm{H}_{2} \mathrm{O}_{2}$ treatment for $24 \mathrm{~h}$. The Hoechst staining assay is capable of detecting condensed chromatin in apoptotic cells (16). The Hoechst staining results (Fig. 3A) indicated that the proportion of apoptotic cells was significantly increased in the $\mathrm{H}_{2} \mathrm{O}_{2}$ treatment group compared with that in the control group, but this was attenuated by pre-treatment with Sal B (Fig. 3C). To further confirm this observation, flow cytometry with Annexin V-FITC/PI double staining was performed. In accordance with the results of the Hoechst staining assay, Annexin V-FITC/PI double staining indicated a similar increase in cell apoptosis in the $\mathrm{H}_{2} \mathrm{O}_{2}$ group compared with that in the control group. However, a dose-dependent decrease in the apoptotic rate of the HUVECs was achieved by pre-treatment with Sal B (Fig. 3C and D). In addition, the activity of caspase-3, a key enzyme in the apoptotic process, was detected. The $\mathrm{H}_{2} \mathrm{O}_{2}$-induced increase in the activity of caspase-3 was attenuated by pre-treatment with Sal B (Fig. 3H). Furthermore, the levels of apoptosis-associated proteins cytochrome $\mathrm{c}$ and cleaved caspase-3 were detected by western blotting. The results indicated that pre-treatment with Sal B decreased the $\mathrm{H}_{2} \mathrm{O}_{2}$-induced cytoplasmic levels of cytochrome $c$ and cleaved caspase-3 in the HUVECs (Fig. 3E-G). These results all demonstrated that Sal B protects HUVECs from oxidative stress-induced apoptosis in vitro.

Autophagy protects $\mathrm{HUVECs}$ against $\mathrm{H}_{2} \mathrm{O}_{2}$-induced apoptosis. An increasing number of studies have suggested that an appropriate level of autophagy may protect cells against cell injury (17). To determine whether autophagy protects HUVECs from apoptosis under oxidative stress, the autophagy inhibitor 3-MA and the mTOR inhibitor rapamycin were used. First, upregulation of LC3-II (autophagy-associated protein) and downregulation of p62 were observed following stimulation by $\mathrm{H}_{2} \mathrm{O}_{2}$ in comparison with the control group, and these changes were abrogated by 3-MA but enhanced by rapamycin (Fig. 4D-F). These results suggest that autophagy was induced in this cell model of oxidative stress. Regarding the effect of autophagy on cell viability, it was observed that the viability in the $\mathrm{H}_{2} \mathrm{O}_{2}$ group was decreased compared with that in the control group, whereas rapamycin increased cell viability and 3-MA decreased cell viability compared with that in the $\mathrm{H}_{2} \mathrm{O}_{2}$ group (Fig. 4A). Flow cytometric analysis was then performed for further confirmation, and the results indicated that apoptosis in the rapamycin group was decreased, whereas that in the 3-MA group was increased, compared with that in the $\mathrm{H}_{2} \mathrm{O}_{2}$ group (Fig. 4B and $\mathrm{C}$ ), further suggesting that autophagy may inhibit apoptosis.

In addition, apoptosis-associated proteins were determined for further confirmation, and the results indicated that, compared with those in the $\mathrm{H}_{2} \mathrm{O}_{2}$ group, rapamycin decreased 

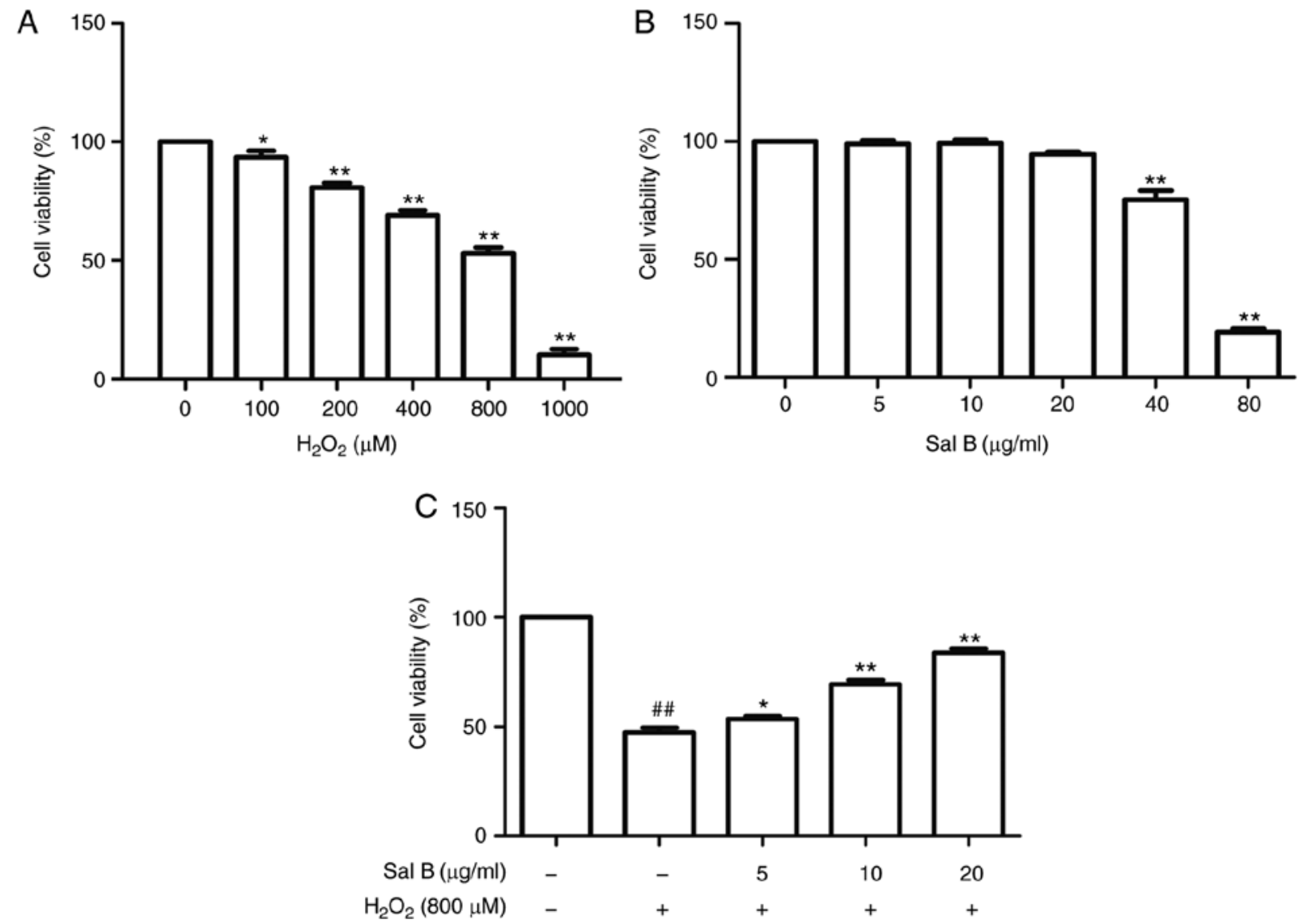

Figure 2. Cell viability determination via MTT assay. (A) HUVECs were treated with $\mathrm{H}_{2} \mathrm{O}_{2}$ at the indicated concentrations. (B) HUVECs were incubated with the indicated concentrations of Sal B for $24 \mathrm{~h}$. (C) HUVECs were pretreated with Sal B (5, 10 and $20 \mu \mathrm{g} / \mathrm{ml})$ for $24 \mathrm{~h}$ and then treated with or without $\mathrm{H}_{2} \mathrm{O}_{2}(800 \mu \mathrm{M})$ for $24 \mathrm{~h}$. The data are representative of three independent experiments (mean $\pm \mathrm{SEM}$ ); ${ }^{*} \mathrm{P}<0.05$ and ${ }^{* *} \mathrm{P}<0.01$ compared with the control group, ${ }^{\# \#} \mathrm{P}<0.01$ compared with the control group. HUVECs, human umbilical vein endothelial cells; Sal B, salvianolic acid B; $\mathrm{H}_{2} \mathrm{O}_{2}$, hydrogen peroxide.

the protein levels of cytochrome $c$ and cleaved caspase-3, whereas 3-MA enhanced their levels (Fig. 4G-I). These results suggest that autophagy is a protective mechanism against $\mathrm{H}_{2} \mathrm{O}_{2}$-induced HUVEC apoptosis.

Sal B promotes autophagy in HUVECs under oxidative stress. The HUVECs were transfected with Ad-mCherry-GFP-LC3B followed by challenge with $\mathrm{H}_{2} \mathrm{O}_{2}$ with pretreatment of $20 \mu \mathrm{g} / \mathrm{ml}$ Sal B. The numbers of green, red and yellow spots were increased in the $\mathrm{Sal} \mathrm{B}+\mathrm{H}_{2} \mathrm{O}_{2}$ group compared with those in the $\mathrm{H}_{2} \mathrm{O}_{2}$ group (Fig. 5A and B). These results suggested that Sal B promotes autophagy flux. To further confirm whether Sal B promotes autophagy in HUVECs under oxidative stress, the HUVECs were pre-treated with different concentrations of Sal B $(5,10$ and $20 \mu \mathrm{g} / \mathrm{ml})$, followed by incubation with $800 \mu \mathrm{M} \mathrm{H}_{2} \mathrm{O}_{2}$ for $24 \mathrm{~h}$, and the expression levels of LC3-II, Beclin-1 and p62 were detected. The results indicated that LC3-II and Beclin-1 were increased, and p62 was decreased by $\mathrm{H}_{2} \mathrm{O}_{2}$ treatment, and these changes were enhanced by Sal B in a concentration-dependent manner (Fig. 5C-F). Taken together, these results indicate that Sal B enhances autophagy in HUVECs under oxidative stress.

Sal B promotes autophagy to decrease $\mathrm{H}_{2} \mathrm{O}_{2}$-induced apoptosis in HUVECs. The HUVECs were pre-treated with different concentrations of Sal B (5, 10 and $20 \mu \mathrm{g} / \mathrm{ml})$, followed by incubation with $800 \mu \mathrm{M} \mathrm{H}_{2} \mathrm{O}_{2}$ and optionally with 4 mM 3-MA for $24 \mathrm{~h}$. As presented in Fig. 6A-C, Sal B increased the cell viability and decreased the apoptosis of HUVECs compared with those in the $\mathrm{H}_{2} \mathrm{O}_{2}$ group. However, these effects of Sal B were attenuated by 3-MA, suggesting that Sal B increased autophagy to decrease apoptosis. To confirm this, the apoptosis-associated proteins cytochrome $c$ and cleaved-caspase 3, and the autophagy-associated proteins LC3-II and p62 were detected in the above treatment groups. The results indicated that the addition of 3-MA significantly decreased the expression of LC3-II and increased that of p62 in the HUVECs compared with those in the $20 \mu \mathrm{g} / \mathrm{ml} \mathrm{Sal} \mathrm{B}+\mathrm{H}_{2} \mathrm{O}_{2}$ group (Fig. 6D-F). Furthermore, 3-MA decreased the expression levels of cytochrome $c$ and cleaved caspase-3 compared with those in the $20 \mu \mathrm{g} / \mathrm{ml} \mathrm{Sal} \mathrm{B}+\mathrm{H}_{2} \mathrm{O}_{2}$ group (Fig. 6G-I). These results confirmed that the increased autophagic activity induced by Sal B has a protective effect against $\mathrm{H}_{2} \mathrm{O}_{2}$-induced apoptosis in HUVECs.

Sal B activates cell autophagy through the AMPK/mTOR pathway under oxidative stress. As autophagy may be induced via several different pathways, the present study aimed to determine which of them is promoted by Sal B via western blot analysis of AKT, p-AKT, AMPK, p-AMPK, mTOR and p-mTOR. As is presented in Fig. 7A-D, treatment with Sal B $(5,10$ and $20 \mu \mathrm{g} / \mathrm{ml})$ followed by incubation with $800 \mu \mathrm{M} \mathrm{H}_{2} \mathrm{O}_{2}$ 


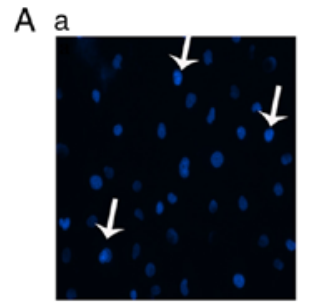

B a

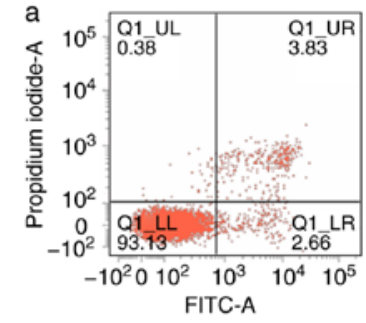

d

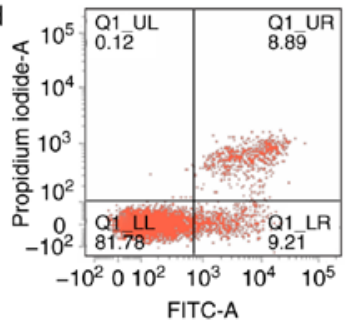

C
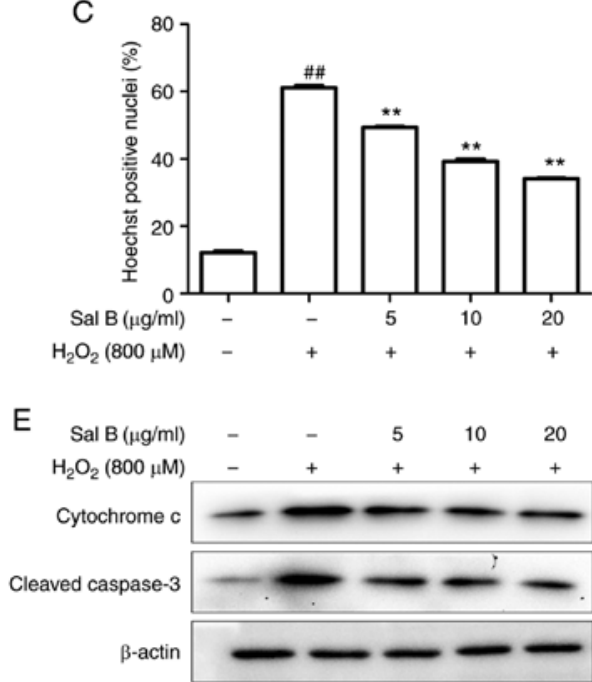

G

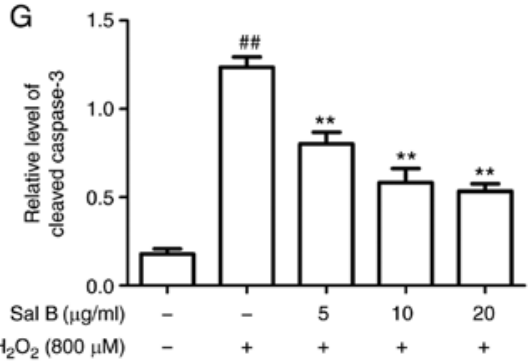

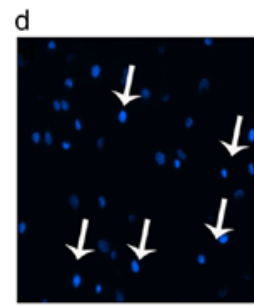
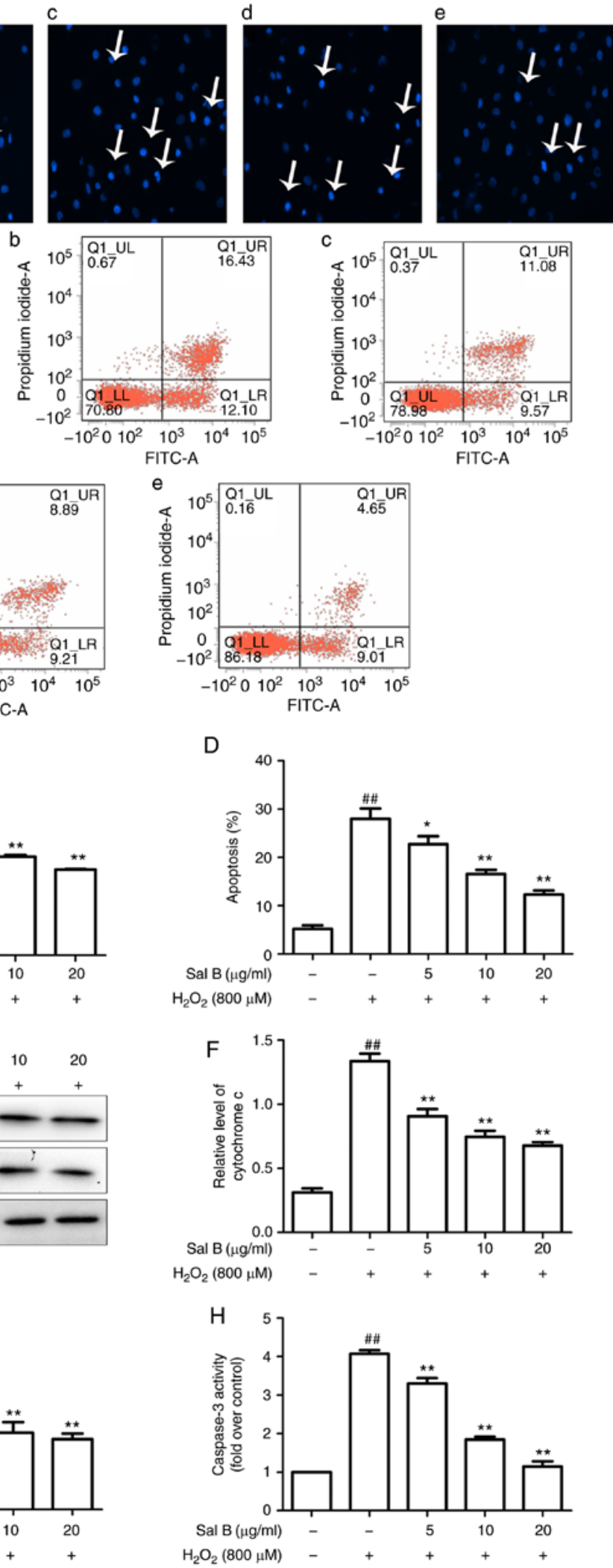

Figure 3. Sal B inhibits $\mathrm{H}_{2} \mathrm{O}_{2}$-induced apoptosis in HUVECs. (A) HUVECs were treated with $\mathrm{H}_{2} \mathrm{O}_{2}$ in the presence or absence Sal B, and the cells were stained with Hoechst 33258 (white arrows indicate apoptotic cells; magnification, x200). (B) Flow cytometric analysis of HUVEC apoptosis was stained by Annexin V-FITC/propidium iodide double staining; (a) control group; (b) $\mathrm{H}_{2} \mathrm{O}_{2}$ group; (c) $\mathrm{H}_{2} \mathrm{O}_{2}+5 \mu \mathrm{g} / \mathrm{ml} \mathrm{Sal} \mathrm{B} \mathrm{group;} \mathrm{(d),} \mathrm{H}_{2} \mathrm{O}_{2}+10 \mu \mathrm{g} / \mathrm{ml} \mathrm{Sal} \mathrm{B} \mathrm{group;}$ (e) $\mathrm{H}_{2} \mathrm{O}_{2}+20 \mu \mathrm{g} / \mathrm{ml} \mathrm{Sal} \mathrm{B} \mathrm{group.} \mathrm{(C)} \mathrm{Rate} \mathrm{of} \mathrm{apoptosis} \mathrm{quantified} \mathrm{by} \mathrm{Hoechst.} \mathrm{(D)} \mathrm{Rate} \mathrm{of} \mathrm{apoptosis} \mathrm{quantified} \mathrm{by} \mathrm{flow} \mathrm{cytometry;} \mathrm{Sal} \mathrm{B} \mathrm{decreased} \mathrm{apoptosis}$ of the HUVECs induced by $\mathrm{H}_{2} \mathrm{O}_{2}$. Data are representative of three independent experiments (mean \pm SEM); ${ }^{\# \#} \mathrm{P}<0.01$ compared with the control group; ${ }^{*} \mathrm{P}<0.05$ and ${ }^{* *} \mathrm{P}<0.01$ compared with the $\mathrm{H}_{2} \mathrm{O}_{2}$ group. (E) Sal B decreased $\mathrm{H}_{2} \mathrm{O}_{2}$-induced caspase-3 activity. ${ }^{\# \#} \mathrm{P}<0.01$ compared with the control group; ${ }^{* *} \mathrm{P}<0.01$ compared with the $\mathrm{H}_{2} \mathrm{O}_{2}$ group. (F) HUVECs were incubated with different concentrations $(5,10,20 \mu \mathrm{g} / \mathrm{ml})$ of Sal B for $24 \mathrm{~h}$ and then stimulated with $\mathrm{H}_{2} \mathrm{O}_{2}$ $(800 \mu \mathrm{M})$ for $24 \mathrm{~h}$. The protein levels of cytochrome $c$ and cleaved caspase-3 or $\beta$-actin were determined by western blotting. Bar charts show the quantification of $(\mathrm{G})$ cytochrome $c$ and $(\mathrm{H})$ cleaved caspase-3. Relative protein levels are presented as the mean \pm SEM of the optical density from three separate experiments. ${ }^{\# \#} \mathrm{P}<0.01$ compared with control group; ${ }^{* *} \mathrm{P}<0.01$ compared with $\mathrm{H}_{2} \mathrm{O}_{2}$ group. HUVECs, human umbilical vein endothelial cells; Sal $\mathrm{B}$, salvianolic acid $\mathrm{B}$; $\mathrm{H}_{2} \mathrm{O}_{2}$, hydrogen peroxide. 

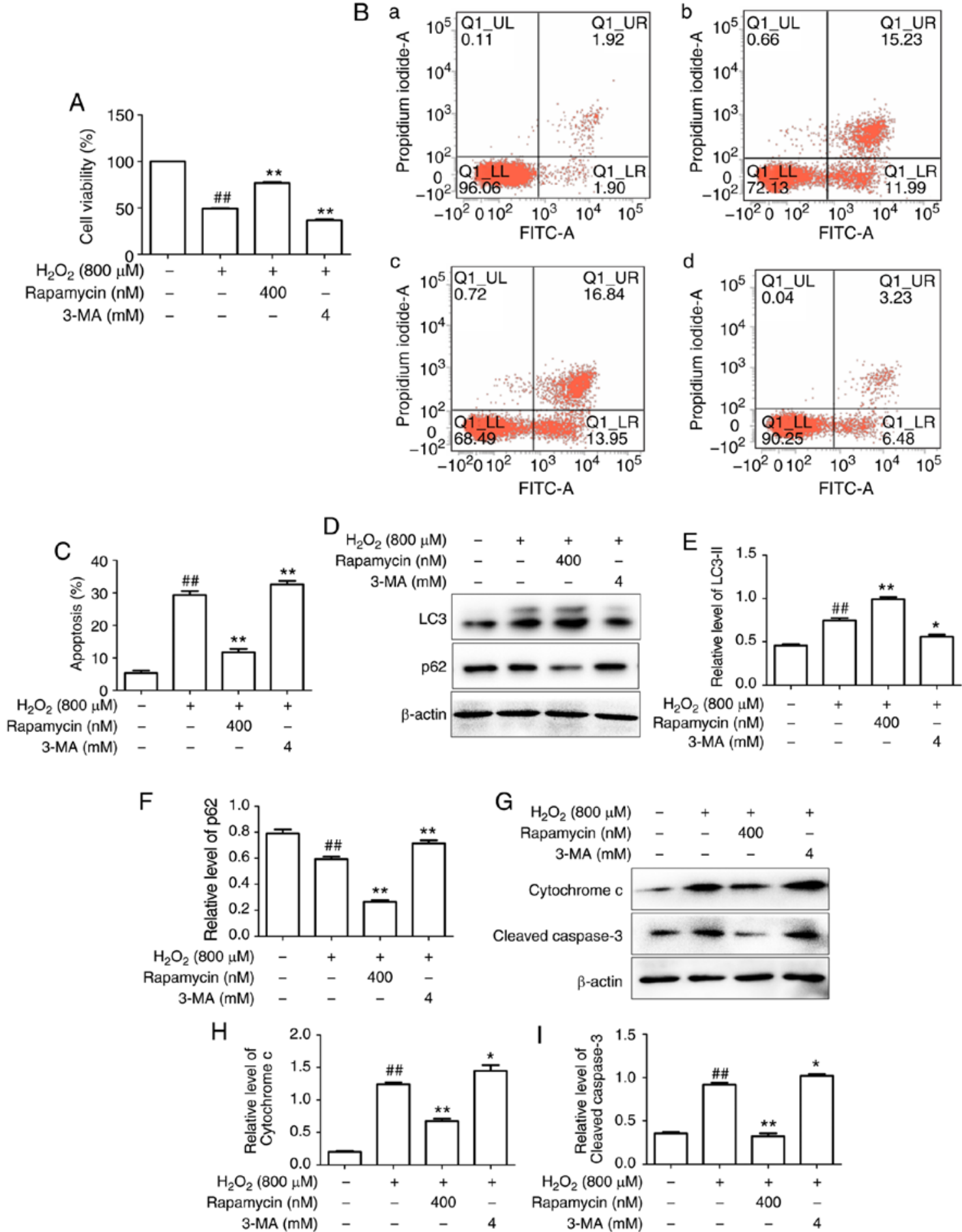

Figure 4. Autophagy decreases the apoptosis of HUVECs induced by $\mathrm{H}_{2} \mathrm{O}_{2}$. (A) Rapamycin increased and 3-MA decreased the cell viability of HUVECs induced by $\mathrm{H}_{2} \mathrm{O}_{2}$. (B) Flow cytometric analysis of HUVEC apoptosis with staining by Annexin V-FITC/propidium iodide double staining; (a) control group; (b) $\mathrm{H}_{2} \mathrm{O}_{2}$ group; (c) $\mathrm{H}_{2} \mathrm{O}_{2}+3$-MA group; (d) $\mathrm{H}_{2} \mathrm{O}_{2}+$ Rapamycin group. (C) Rate of apoptotic cells quantified by flow cytometry; rapamycin decreased and 3-MA increased apoptosis of the HUVECs induced by $\mathrm{H}_{2} \mathrm{O}_{2} \cdot{ }^{\# \#} \mathrm{P}<0.01$ compared with the control group; ${ }^{* *} \mathrm{P}<0.01$ compared with the $\mathrm{H}_{2} \mathrm{O}_{2}$ group. (D) Protein levels of LC3 and p62 or $\beta$-actin were determined by western blotting. Bar charts show the quantification of (E) LC3-II and (F) p62. (G) Protein levels of cytochrome $c$ and cleaved caspase- 3 or $\beta$-actin were determined by western blotting. Bar charts show the quantification of $(\mathrm{H})$ cytochrome $c$ and (I) cleaved caspase-3. The relative protein levels of cytochrome $c$, cleaved caspase-3, LC3-II and p62 are presented as the mean \pm SEM of the optical density from three separate experiments. ${ }^{\# \#} \mathrm{P}<0.01$ compared with the control group; ${ }^{*} \mathrm{P}<0.05$ and ${ }^{* *} \mathrm{P}<0.01$ compared with the $\mathrm{H}_{2} \mathrm{O}_{2}$ group. HUVECs, human umbilical vein endothelial cells; Sal B, salvianolic acid B; 3-MA, 3-methyladenine; LC3, light chain 3; $\mathrm{H}_{2} \mathrm{O}_{2}$, hydrogen peroxide.

decreased the levels of p-AKT and p-mTOR and increased the levels of p-AMPK in a dose-dependent manner compared with those in the control group. In the group pre-treated with Sal B, the expression of p-AMPK was increased and that of p-mTOR was decreased, whereas p-AKT was not significantly affected, compared with the levels in the $\mathrm{H}_{2} \mathrm{O}_{2}$ group. These results indicate that Sal B may promote autophagy via the AMPK/mTOR signaling pathway, rather than the PI3K/AKT/mTOR pathway. 


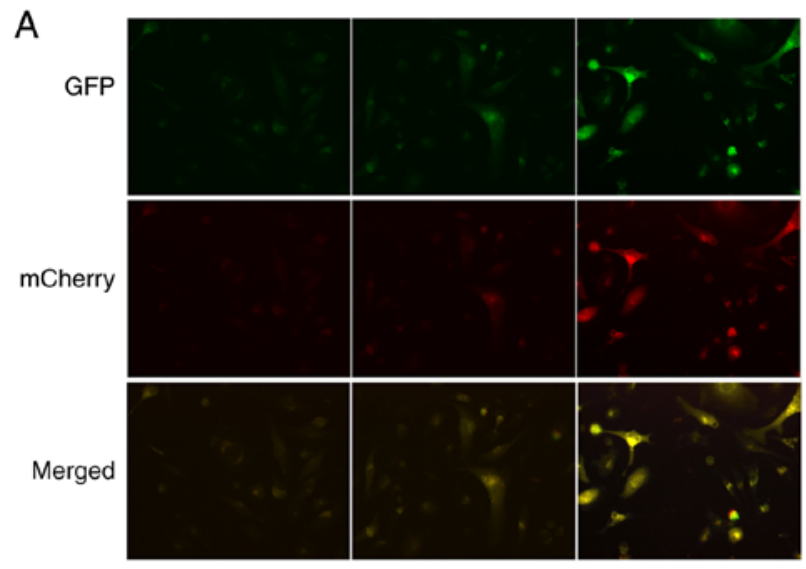

$\mathrm{B}$

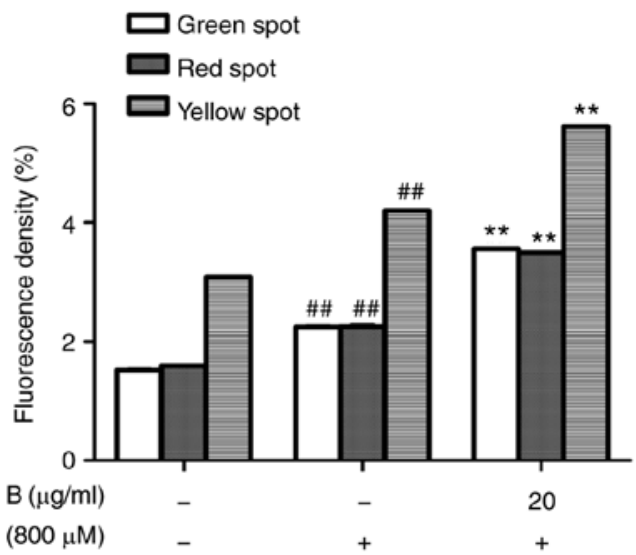

C $\begin{array}{rccccc}\mathrm{Sal} \mathrm{B}(\mu \mathrm{g} / \mathrm{ml}) & - & - & 5 & 10 & 20 \\ \mathrm{H}_{2} \mathrm{O}_{2}(800 \mu \mathrm{M}) & - & + & + & + & +\end{array}$
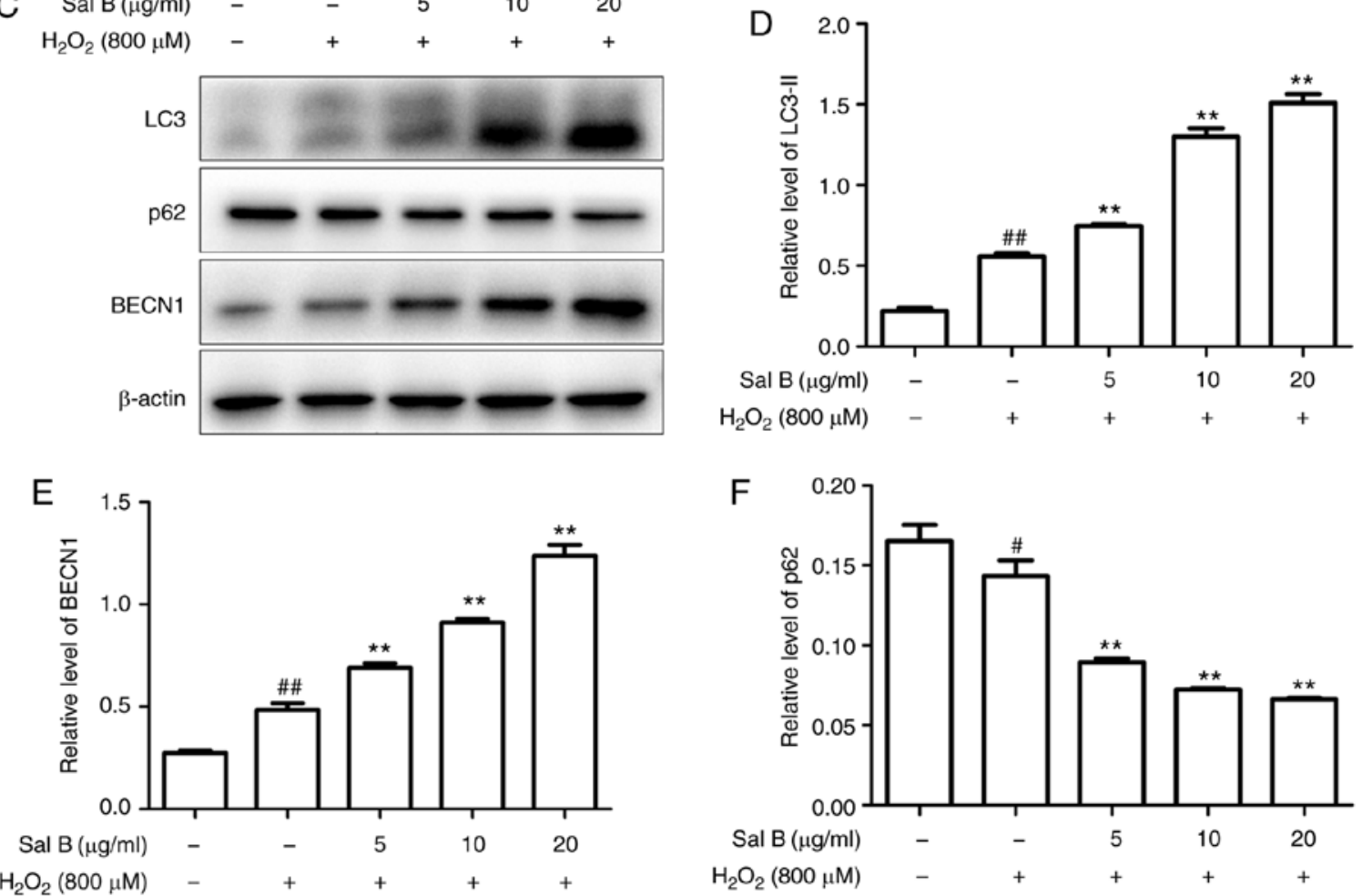

Figure 5. Sal B promotes the autophagy of HUVECs under oxidative stress. (A) Sal B promoted autophagic flux (magnification, x200). (B) Quantitative bar charts of autophagy influx (C) HUVECs were treated with Sal B $(5,10$ and $20 \mu \mathrm{g} / \mathrm{ml})$ for $24 \mathrm{~h}$ and the protein levels of LC3, p62 and Beclin-1 or $\beta$-actin were determined by western blotting. Bar charts show the quantification of (D) LC3-II, (E) Beclin-1 and (F) p62. The relative protein levels of LC3-II, p62 and Beclin-1 are presented as the mean \pm SEM of the optical density from three separate experiments. ${ }^{*} \mathrm{P}<0.05$ and ${ }^{\#} \mathrm{P}<0.01$ compared with the control group; ${ }^{* *} \mathrm{P}<0.01$ compared with the $\mathrm{H}_{2} \mathrm{O}_{2}$ group. HUVECs, human umbilical vein endothelial cells; Sal B, salvianolic acid B; LC3, light chain 3; $\mathrm{H}_{2} \mathrm{O}_{2}$, hydrogen peroxide.

To confirm the mechanism of autophagy promoted by Sal B, the AMPK inhibitor compound $\mathrm{C}$ was used to determine the resulting effect on the level of p-AMPK. In the group that was co-treated with compound $\mathrm{C}$, the level of p-mTOR was increased and that of $\mathrm{p}$-AMPK was decreased compared with levels in the Sal B $+\mathrm{H}_{2} \mathrm{O}_{2}$ group (Fig. 7E-G), which confirmed AMPK/mTOR signaling as at least part of the underlying molecular mechanism.

\section{Discussion}

One of the factors causing atherosclerosis is vascular EC apoptosis, which may be triggered by free radicals, oxidized low-density lipoprotein (ox-LDL) and the activation of blood platelets. Previous studies have indicated that the number of vascular ECs is decreased by apoptosis, and the prevention of endothelial activation and reduction of endothelial injury are key to the prevention and treatment of AS (18-20). Therefore, the present study investigated a strategy to inhibit vascular $\mathrm{EC}$ apoptosis and thereby prevent atherosclerosis. Numerous studies have confirmed that Sal B has an anti-atherosclerotic effect due to its anti-oxidative and anti-inflammatory actions, and its suppression of the presence of foam cells (21-25). Therefore, Sal B exerts a dual effect, namely the protection of vascular ECs and a decrease in the formation of a fibrous cap that stabilizes a plaque, which renders Sal B suitable for 

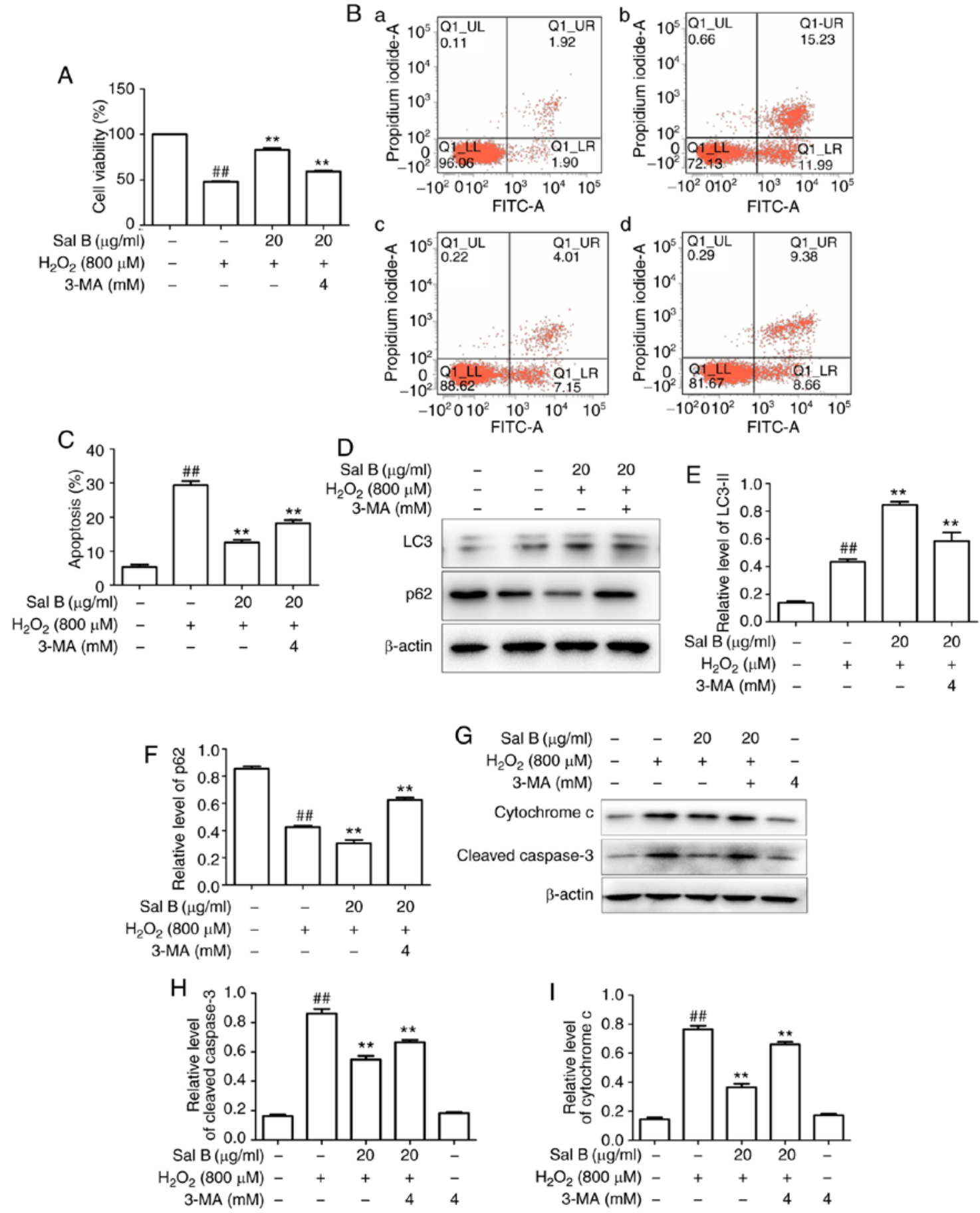

Figure 6. Sal B promotes autophagy to decrease $\mathrm{H}_{2} \mathrm{O}_{2}$-induced apoptosis in HUVECs. (A) Sal B promoted the cell viability of HUVECs by $\mathrm{H}_{2} \mathrm{O}_{2}$ and 3-MA partly attenuated this. The results are expressed as the mean $\pm \mathrm{SEM}$ of three independent experiments. ${ }^{\# \#} \mathrm{P}<0.01$ compared with the control group; ${ }^{* *} \mathrm{P}<0.01$ compared with the $\mathrm{H}_{2} \mathrm{O}_{2}$ group. (B) Flow cytometric analysis of HUVEC apoptosis stained with Annexin V-FITC/propidium iodide double staining; (a) control group; (b) $\mathrm{H}_{2} \mathrm{O}_{2}$ group; (c) Sal B $+\mathrm{H}_{2} \mathrm{O}_{2}$ group; (d) Sal B + 3-MA group. (C) Rate of apoptotic cells quantified by flow cytometry; Sal B decreased apoptosis and 3-MA partly attenuated it. ${ }^{\# \#} \mathrm{P}<0.01$ compared with the control group; ${ }^{* *} \mathrm{P}<0.01$ compared with the $\mathrm{H}_{2} \mathrm{O}_{2}$ group. (D) HUVECs were treated with Sal B (5, 10 and $20 \mu \mathrm{g} / \mathrm{ml}$ ) for $24 \mathrm{~h}$ and the protein levels of LC3 or $\beta$-actin were determined by western blotting. Bar charts show the quantification of (E) LC3-II and (F) p62. The relative protein levels of LC3-II and p62 are presented as the mean \pm SEM of the optical density from three separate experiments. (G) HUVECs were treated with Sal B $(5,10$ and $20 \mu \mathrm{g} / \mathrm{ml})$ for $24 \mathrm{~h}$ and the protein level of cytochrome $c$ cleaved caspase-3 was determined by western blotting. Quantification of (H) cleaved caspase-3 and (I) cytochrome $c$ are presented as the mean \pm SEM of three independent experiments, ${ }^{\# \# ~} \mathrm{P}<0.01$ compared with the control group; ${ }^{* *} \mathrm{P}<0.01$ compared with the $\mathrm{H}_{2} \mathrm{O}_{2}$ group. HUVECs, human umbilical vein endothelial cells; Sal B, salvianolic acid B; LC3, light chain 3; $\mathrm{H}_{2} \mathrm{O}_{2}$, hydrogen peroxide.

treating atherosclerosis, for example, through resolving recurrence by stabilizing plaques or as a co-treatment for enhancing the efficiency of other anti-atherosclerotic treatments. The results of the present study indicate that Sal B inhibited the apoptosis of vascular ECs under oxidative stress. In addition, it was indicated that the induction of autophagy serves an important role in the anti-apoptotic effects of Sal B under oxidative stress. Further mechanistic investigation indicated 
A $\quad$ Sal B $(\mu \mathrm{g} / \mathrm{ml}) \quad-\quad \begin{array}{llll}5 & 5 & 10 & 20\end{array}$

$\mathrm{H}_{2} \mathrm{O}_{2}(800 \mu \mathrm{M})++++$

p-AKT

AKT

p-AMPK

AMPK

p-mTOR

mTOR

$\beta$-actin

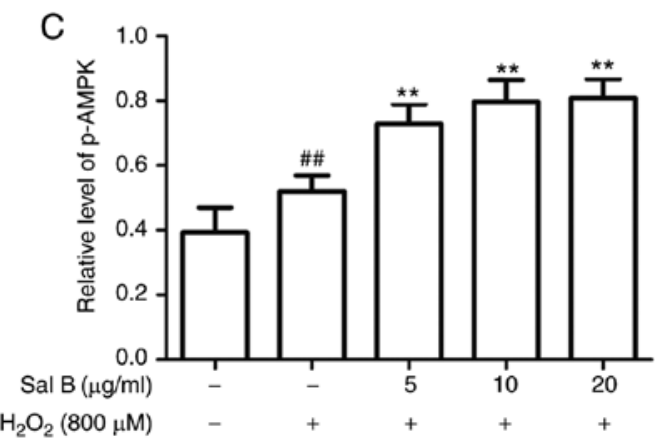

E

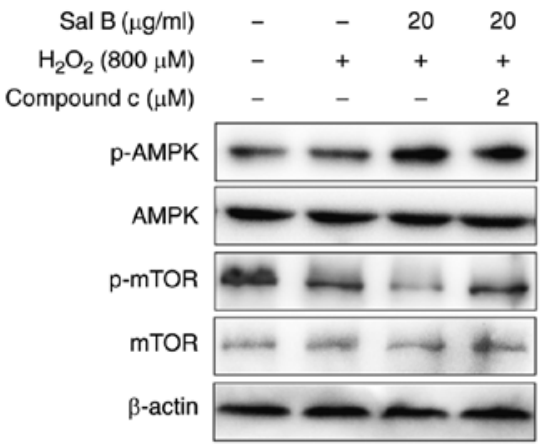

B
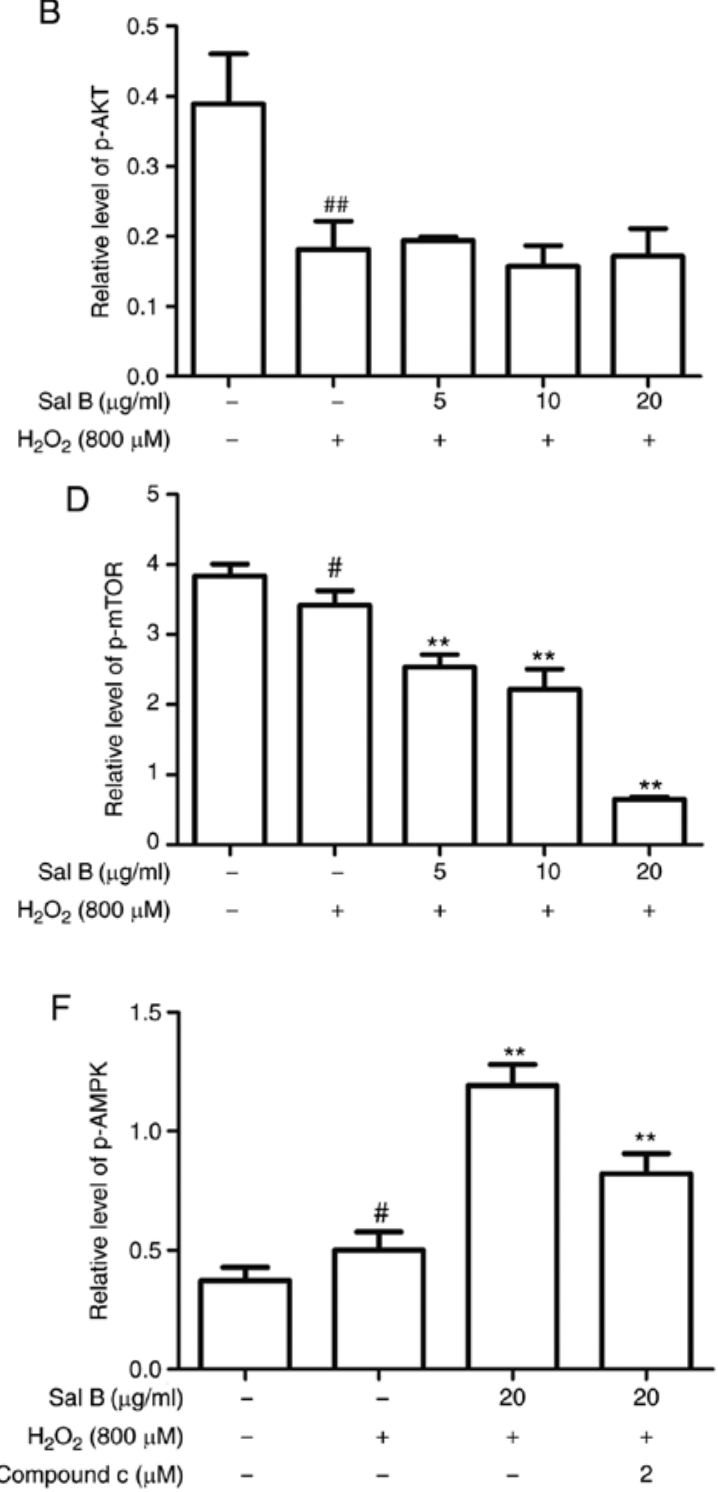

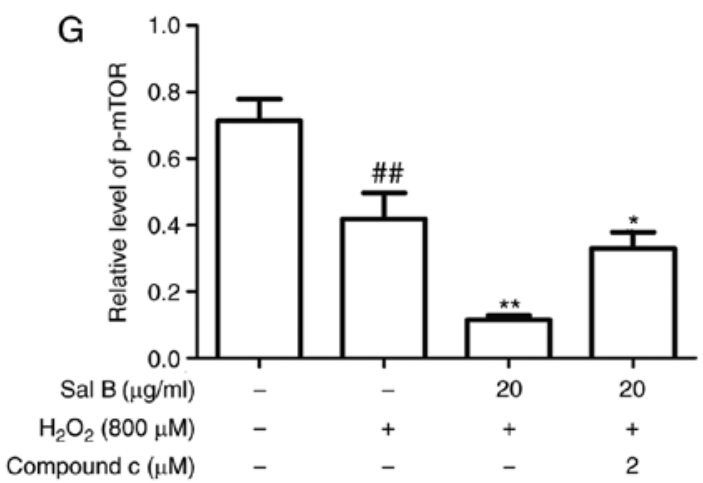

Figure 7. Sal B increases the protein expression of p-AMPK and decreases that of p-mTOR, resulting in a decreased rate of apoptosis, whereas compound C decreases the levels of p-AMPK and increases the rate of apoptosis. (A) Sal B mediated the protein expression of p-AMPK and p-mTOR, but did not affect p-AKT. Quantification of (B) p-AKT, (C) p-AMPK and (D) p-mTOR are expressed as the mean \pm SEM of three independent experiments; ${ }^{*} \mathrm{P}<0.05$ and ${ }^{\# \#} \mathrm{P}<0.01$ compared with the control group; ${ }^{* *} \mathrm{P}<0.01$ compared with the $\mathrm{H}_{2} \mathrm{O}_{2}$ group. (E) Sal B increased the protein expression of p-AMPK and decreased that of p-mTOR, which was partly attenuated by compound $C$ attenuated it partly. Quantification of (F) p-AMPK and (G) p-mTOR are presented as the mean \pm SEM of three independent experiments. ${ }^{*} \mathrm{P}<0.05$ and ${ }^{\# *} \mathrm{P}<0.01$ compared with the control group; ${ }^{*} \mathrm{P}<0.05$ and ${ }^{* *} \mathrm{P}<0.01$ compared with the $\mathrm{H}_{2} \mathrm{O}_{2}$ group. Sal $\mathrm{B}$, salvianolic acid B; AMPK, AMP kinase; mTOR, mammalian target of rapamycin; p-, phosphorylated; $\mathrm{H}_{2} \mathrm{O}_{2}$, hydrogen peroxide.

that Sal B induced autophagy in vascular ECs under oxidative stress by activating the AMPK/mTOR pathway. In in vitro experiments, $\mathrm{H}_{2} \mathrm{O}_{2}$ is used as cell injury inducer (26). In the present study, $800 \mu \mathrm{M} \mathrm{H}_{2} \mathrm{O}_{2}$ led to the apoptosis of vascular ECs, as the survival rate decreased to $53.02 \pm 6.07 \%$. Of note, Sal B suppressed $\mathrm{H}_{2} \mathrm{O}_{2}$-induced apoptosis in HUVECs, 
suggesting that Sal B has the potential to treat atherosclerosis by preventing vascular EC apoptosis under oxidative stress conditions. Wu et al (27) reported that Sal B protects ECs against oxidative stress-induced cell injury through upregulating glucose-regulated protein 78. Furthermore, Chen et al (28) demonstrated the protective effect of Sal B against ox-LDL-induced HUVEC injury and apoptosis. In line with this, another study confirmed that Sal B protects vascular ECs against injury induced by oxidative stress (29). These previous studies further support the present observations, and based on these studies, the underlying molecular mechanisms and pathways were then further investigated.

The association between autophagy and apoptosis is a focus of research. Autophagy is an intracellular catabolic process in which long-lived proteins are recycled and damaged organelles are eliminated, and under certain conditions, it also promotes apoptosis (30). Autophagy has been confirmed to induce apoptosis under high stress conditions (31). However, autophagy may be tuned to maintain cellular homeostasis under different stresses through the inhibition of apoptosis (32). Certain studies have indicated that autophagy may have two different effects to either prevent or induce apoptosis, depending on cell function, disease stage, therapeutic schedule and cell microenvironment (33). It is well-known that autophagy has a vital role in protecting the cardiovascular system (34). A previous study demonstrated the cardioprotective effect of Sal B on acute myocardial infarction by promoting autophagy and neovascularization and inhibiting apoptosis (35). It has been shown that autophagy serves to eliminate injured mitochondria when a large number of apoptotic factors are released into the cytoplasm. Therefore, promotion of the autophagy of injured cells may provide a novel anti-atherosclerotic strategy. In the present study, the autophagy inhibitor, 3-MA, and the autophagy inducer, rapamycin, were used to confirm the roles of autophagy in HUVECs. Compared with the control group, treatment of the HUVECs with 3-MA increased apoptosis, decreased autophagy marker LC3-II, and increased the levels of p62 and the apoptosis-associated cytochrome $c$ and cleaved-caspase 3 proteins. However, the autophagy inducer rapamycin produced the opposite effect, namely decreasing apoptosis, increasing LC3-II and decreasing the levels of p62, cytochrome $\mathrm{c}$ and cleaved caspase-3. This indicated that autophagy has an important role in regulating apoptosis to protect cells.

As the results of the present study indicated that Sal B protects HUVECs against $\mathrm{H}_{2} \mathrm{O}_{2}$-induced cell injury, loss- and gain-of-function experiments were then used to assess the possible involvement of autophagy as an underlying mechanism. Pre-treatment with Sal B followed by incubation with $800 \mu \mathrm{M} \mathrm{H}_{2} \mathrm{O}_{2}$ resulted in the upregulation of LC3-II and Beclin-1 and the downregulation of p62, in addition to the upregulation of autophagic influx, indicating that autophagy was promoted to protect the cell. However, simultaneous treatment with 3-MA partly eliminated this protective effect by Sal B. Therefore, the promotion of autophagy may be one of the mechanisms by which Sal B prevents apoptosis under oxidative stress. Autophagy is regulated by numerous complex signaling pathways, including AMPK, mTOR and Bcl-2/Beclin-2 (36). The mTOR signaling pathway serves a crucial role in autophagy (37); in order to adapt to energy metabolism under stress, AMPK is activated and then inhibits mTOR, inducing the activation of autophagy (38). mTOR is an energy sensor that is contrary to AMPK (39), which is suppressed when energy is poor and is activated when energy is abundant. It is situated downstream of pro-growth factors and pro-synthetic metabolic factors (40). PI3K/Akt/mTOR and AMPK/mTOR signaling have been investigated in numerous studies as autophagy signaling pathways. AKT phosphorylated mTOR to generate activated p-mTOR and triggers downstream signaling to inhibit autophagy. When a cell is under oxidative stress, serine/threonine kinase 11 may lead to the phosphorylation of AMPK. p-AMPK negatively regulates the mTOR signaling pathway to promote autophagy (36). In the present study, pre-treatment with Sal B significantly increased the level of p-AMPK and decreased the level of p-mTOR, but had no effect on the level of p-AKT. Of note, the AMPK inhibitor, compound $\mathrm{C}$, decreased $\mathrm{p}-\mathrm{mTOR}$ and increased p-AMPK. In addition, as presented in the chemical structure of Sal B in Fig. 1, the molecule bears hydroxyl groups on a phenol ring that exert potent anti-oxidative effects which is unlike the effect of other activators of autophagy, including rapamycin, which directly combines with mTOR. From the present results, it is evident that Sal B protects HUVECs from oxidative stress via the AMPK/mTOR pathway. Regarding the mechanisms of other autophagy-induced antioxidants, resveratrol acts via the AMPK/Sirtuin 1/autophagy pathway (41), and curcumin activates autophagy via the PI3K/AKT/mTOR pathway (42). The results of the present study revealed that Sal B has similarities with and differences from certain other autophagy-inducing antioxidants.

In conclusion, the results of the present study indicate that Sal B has the ability to protect HUVECs from apoptosis by promoting autophagy under oxidative stress, and the promotion of autophagy induced by Sal B is mediated via the upregulated phosphorylation of AMPK and the downregulation of mTOR signaling.

\section{Acknowledgements}

The authors would like to thank the Affiliated Hospital of Southwest Medical University and The Drug and Food Function Research Center of Southwest Medical University for providing laboratories in which to perform experiments.

\section{Funding}

The present study was supported by grants from the technology bureau of Luzhou city (grant no. 2015LZCYD-S03), the Technology Bureau of Luzhou City-Southwest Medical University (grant no. 2018LZXNYD-PT02).

\section{Availability of data and materials}

All data generated or analyzed during this study are included in this published article.

\section{Authors' contributions}

SG designed the experiments, wrote the manuscript and performed the MTT assay, western blotting and Hoechst 33258 
fluorescence staining. SL designed the experiments, wrote the manuscript and performed flow cytometric analysis, the caspase-3 activity assay and mCherry-GFP-LC3B transfection. QL, FZ, MS and ZW assisted with experimental design and analyzed the data. SW assisted with experimental design and wrote the manuscript.

\section{Ethics approval and consent to participate}

Not applicable.

\section{Patient consent for publication}

Not applicable.

\section{Competing interests}

The authors declare that they have no competing interests.

\section{References}

1. Sitia S, Tomasoni L, Atzeni F, Ambrosio G, Cordiano G Catapano A, Tramontana S, Perticone F, Naccarato P, Camici P, et al: From endothelial dysfunction to atherosclerosis. Autoimmun Rev 9: 830-834, 2010.

2. Zhang C: The role of inflammatory cytokines in endothelial dysfunction. Basic Res Cardiol 103: 398-406, 2008.

3. Vanhoutte PM: Endothelial dysfunction: The first step toward coronary arteriosclerosis. Circ J 73: 595-601, 2009.

4. Vita JA: Endothelial function. Circulation 124: e906-e912, 2011.

5. Mizushima N, Levine B, Cuervo AM and Klionsky DJ: Autophagy fights disease through cellular self-digestion. Nature 451: 1069-1075, 2008 .

6. Rubinsztein DC: The roles of intracellular protein-degradation pathways in neurodegeneration. Nature 443: 780-786, 2006.

7. Shimomura H, Terasaki F, Hayashi T, Kitaura Y, Isomura T and Suma H: Autophagic degeneration as a possible mechanism of myocardial cell death in dilated cardiomyopathy. Jpn Circ J 65: 965-968, 2001

8. Starke RD, Ferraro F, Paschalaki KE, Dryden NH, McKinnon TA, Sutton RE, Payne EM, Haskard DO, Hughes AD, Cutler DF, et al: Endothelial von Willebrand factor regulates angiogenesis. Blood 117: 1071-1080, 2011.

9. Zhang QW, Zhang Y, Li JP and Ma H: Determination of salvianolic acid $B$ in the radix of Salvia miltiorrhiza Bge. by HPLC. Zhongguo Zhong Yao Za Zhi 26: 848-849, 2001 (In Chinese).

10. Song Q, Han X, Xue Y, Song T, Chu X, Zhang X, Zhang Y, Zhang Y, Zhang J and Chu L: Effects of salvianolic acid B on L-type calcium channels and myocardial contractility in isolated rat ventricular myocytes and $\mathrm{hERG} \mathrm{K}^{+}$channels expressed in HEK293 cells. Naunyn Schmiedebergs Arch Pharmacol 390: 791-799, 2017.

11. Zhang JY, Zhang B, Wang M, Wang W, Liao P, Sun GB and Sun XB: Calcium homeostasis and endoplasmic reticulum stress are involved in Salvianolic acid B-offered protection against cardiac toxicity of arsenic trioxide. Oncotarget 8: 97384-97393, 2017.

12. Chang TM, Shi GY, Wu HL, Wu CH, Su YD, Wang HL, Wen HY and Huang HC: Effects of salvianolic Acid B on protein expression in human umbilical vein endothelial cells. Evid Based Complement Alternat Med 2011: 213050, 2011.

13. Ryter SW, Mizumura K and Choi AM: The impact of autophagy on cell death modalities. Int J Cell Biol 2014: 502676, 2014

14. Gao J, Yang G, Pi R, Li R, Wang P, Zhang H, Le K, Chen S and Liu P: Tanshinone IIA protects neonatal rat cardiomyocytes from adriamycin-induced apoptosis. Transl Res 151: 79-87, 2008.

15. Belmokhtar CA, Hillion J and Ségal-Bendirdjian E: Staurosporine induces apoptosis through both caspase-dependent and caspase-independent mechanisms. Oncogene 20: 3354-3362, 2001.

16. Frey T: Nucleic acid dyes for detection of apoptosis in live cells. Cytometry 21: 265-274, 1995.
17. De Meyer GR and Martinet W: Autophagy in the cardiovascular system. Biochim Biophys Acta 1793: 1485-1495, 2009.

18. Sun GB, Qin M, Luo Y, Pan RL, Meng XB, Wang M, Zou YH and Sun XB: Protect effects and the underlying mechanisms of myricitrin against vascular endothelial cells apoptosis induced by oxidative stress. Yao Xue Xue Bao 48: 615-620, 2013 (In Chinese).

19. Su J, Guo WL, Li X, Kang Y and Gao WZ: Protective effects of dioscin in vascular endothelial cells apoptosis induced by oxidized low-density lipoprotein. J Tianjin Med Univ 2: 175-178, 2012.

20. Liu KX, Chen GP, Lin PL, Huang JC, Lin X, Qi JC and Lin QC: Detection and analysis of apoptosis- and autophagy-related miRNAs of mouse vascular endothelial cells in chronic intermittent hypoxia model. Life Sci 193: 194-199, 2018.

21. Wang J, Zhang Y, Guo LL, Wu GJ and Liu RH: Salvianolic acid $\mathrm{B}$ inhibits the TLR4-NF- $\kappa \mathrm{B}-\mathrm{TNF} \alpha$ pathway and attenuates neonatal rat cardiomyocyte injury induced by lipopolysaccharide. Chin J lntegr Med 17: 775-779, 2011

22. Bao Y, Wang L, Xu Y, Yang Y, Wang L, Si S, Cho S and Hong B: Salvianolic acid B inhibits macrophage uptake of modified low density lipoprotein (mLDL) in a scavenger receptor CD36-dependent manner. Atherosclerosis 223: 152-159, 2012

23. Cheng CC, Yang SP, Lin WS, Ho LJ, Lai JH, Cheng SM and Lin WY: Magnesium lithospermate B mediates anti-inflammation targeting activator protein-1 and nuclear factor-kappa $\mathrm{B}$ signaling pathways in human peripheral $\mathrm{T}$ lymphocytes. Int Immunopharmacol 13: 354-361, 2012.

24. Liu M, Ye J, Gao S, Fang W, Li H, Geng B, Zou J, Chen X, Chen S, Zhang L, et al: Salvianolic acid B protects cardiomyocytes from angiotensin II-induced hypertrophy via inhibition of PARP-1. Biochem Biophys Res Commun 444: 346-353, 2014.

25. Quan W, Yin Y, Xi M, Zhou D, Zhu Y, Guan Y, Guo C, Wang Y, Duan J and Wen A: Antioxidant properties of magnesium lithospermate B contribute to the cardioprotection against myocardial ischemia/reperfusion injury in vivo and in vitro. J Tradit Chin Med 33: 85-91, 2013

26. Xue L, Wu Z, Ji XP, Gao XQ and Guo YH: Effect and mechanism of salvianolic acid $\mathrm{B}$ on the myocardial ischemia-reperfusion injury in rats. Asian Pac J Trop Med 7: 280-284, 2014.

27. Wu HL, Li YH, Lin YH, Wang R, Li YB, Tie L, Song QL, Guo DA, Yu HM and Li XJ: Salvianolic acid B protects human endothelial cells from oxidative stress damage: A possible protective role of glucose-regulated protein 78 induction. Cardiovasc Res 81: 148-158, 2009.

28. Chen HM, Luo H, Zeng WB, Liu B, Huang JC, Liu M, Zeng YJ, Zheng Q, Li JQ, Sun XG and Zhou YC: Salvianolic acid B attenuates oxidized low-density lipoprotein-induced endothelial cell apoptosis through inhibition of oxidative stress, p53, and caspase-3 pathways. Chin J Integr Med, 2017.

29. Chen YH, Lin SJ, Chen YL, Liu PL and Chen JW: Anti-inflammatory effects of different drugs/agents with antioxidant property on endothelial expression of adhesion molecules. Cardiovasc Hematol Disord Drug Targets 6: 279-304, 2006

30. Lv XC and Zhou HY: Resveratrol protects H9c2 embryonic rat heart derived cells from oxidative stress by inducing autophagy: Role of p38 mitogen-activated protein kinase. Can J Physiol Pharmacol 90: 655-662, 2012.

31. Valentim L, Laurence KM, Townsend PA, Carroll CJ, Soond S, Scarabelli TM, Knight RA, Latchman DS and Stephanou A: Urocortin inhibits Beclin1-mediated autophagic cell death in cardiac myocytes exposed to ischaemia/reperfusion injury. J Mol Cell Cardiol 40: 846-852, 2006.

32. Amaravadi RK, Yu D, Lum JJ, Bui T, Christophorou MA, Evan GI, Thomas-Tikhonenko A and Thompson CB: Autophagy inhibition enhances therapy-induced apoptosis in a Myc-induced model of lymphoma. J Clin Invest 117: 326-336, 2007.

33. Baehrecke EH: Autophagy: Dual roles in life and death? Nat Rev Mol Cell Biol 6: 505-510, 2005.

34. Ahn J and Kim J: Nutritional status and cardiac autophagy. Diabetes Metab J 37: 30-35, 2013.

35. Lin C, Liu Z, Lu Y, Yao Y, Zhang Y, Ma Z, Kuai M, Sun X, Sun S, Jing Y, et al: Cardioprotective effect of Salvianolic acid B on acute myocardial infarction by promoting autophagy and neovascularization and inhibiting apoptosis. J Pharm Pharmacol 68: 941-952, 2016.

36. Yang Z and Klionsky DJ: Mammalian autophagy: Core molecular machinery and signaling regulation. Curr Opin Cell Biol 22: 124-131, 2010. 
37. Pyo JO, Nah J and Jung YK: Molecules and their functions in autophagy. Exp Mol Med 44: 73-80, 2012.

38. Alers S, Löffler AS, Wesselborg S and Stork B: Role of AMPK-mTOR-Ulk1/2 in the regulation of autophagy: Cross talk, shortcuts, and feedbacks. Mol Cell Biol 32: 2-11, 2012.

39. Inoki K, Kim J and Guan KL: AMPK and mTOR in cellular energy homeostasis and drug targets. Annu Rev Pharmacol Toxicol 52: 381-400, 2012.

40. Dazert E and Hall MN: mTOR signaling in disease. Curr Opin Cell Biol 23: 744-755, 2011.

41. Guo H, Chen Y, Liao L and Wu W: Resveratrol protects HUVECs from oxidized-LDL induced oxidative damage by autophagy upregulation via the AMPK/SIRT1 pathway. Cardiovase Drugs Ther 27: 189-198, 2013.
42. Liu F, Gao S, Yang Y, Zhao X, Fan Y, Ma W, Yang D, Yang A and Yu Y: Antitumor activity of curcumin by modulation of apoptosis and autophagy in human lung cancer A549 cells through inhibiting PI3K/Akt/mTOR pathway. Oncol Rep 39: 1523-1531, 2018.

(i) $\odot$ This work is licensed under a Creative Commons Attribution-NonCommercial-NoDerivatives 4.0 International (CC BY-NC-ND 4.0) License. 